DOI: https://doi.org/10.47405/mjssh.v6i6.840

\begin{tabular}{|c|c|}
\hline 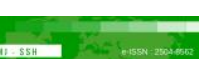 & Malaysian Journal of Social Sciences and Humanities (MJSSH) \\
\hline Malaysian Journal of & Volume 6, Issue 6, June 2021 \\
\hline (Mu-ssH) & e-ISSN : 2504-8562 \\
\hline & $\begin{array}{l}\text { Journal home page: } \\
\text { www.msocialsciences.com }\end{array}$ \\
\hline
\end{tabular}

\title{
Peluang China Aplikasi Model Taiwan Relations Act (TRA) dalam Konflik Israel- Palestin sebagai Palestine Relations Act (PRA) dan Meluaskan Kuasa Ke Organisation of Islamic Cooperation (OIC) dan Non-Aligned Movement (NAM)
}

\author{
Md. Shukri Shuib' \\ ${ }^{1}$ School of International Studies (SOIS), College of Law, Government, and International Studies, \\ Universiti Utara Malaysia (UUM)
}

Correspondence: Md. Shukri Shuib (wacanashukri@gmail.com)

\begin{abstract}
Abstrak
Penyelesaian Konflik Israel-Palestin telah menjadi agenda global yang tidak hanya membabitkan negara tertentu tetapi juga melibatkan organisasi antarabangsa seperti Pertubuhan Bangsa-Bangsa Bersatu (PBB), Organisation of Islamic Cooperation (OIC) dan Non-Aligned Movement (NAM) yang gagal diselesaikan semenjak tahun 1948. Serangan ke atas negara dan korban nyawa rakyat Palestin telah menjadi perkara biasa dalam senario keselamatan antarabangsa. China yang merupakan antara kuasa besar dan ahli Majlis Keselamatan PBB telah memberi perhatian terhadap nasib Palestin telah menarik perhatian sebagai negara yang mampu membawa penyelesaian konflik. Dalam masa yang sama China turut memiliki peluang melalui konsep hubungan Amerika Syarikat-Taiwan dalam Taiwan Relations Act (TRA) sebagai model penyelesaian yang akan memberikan manfaat yang besar kepada Palestin dan China sendiri dalam aspek politik, ekonomi dan penyelesaian masalah dalaman China. Objektif kajian ini adalah untuk menjelaskan konsep TRA boleh dijadikan sebagai asas kepada pembentukan Palestine Relations Act (PRA) antara China dan Palestin yang akan membuka peluang kepada perluasan pengaruh kepada 57 buah negara OIC dan 120 buah negara NAM yang secara langsung memberikan sokongan kepada China bagi menggantikan Soviet Union (Rusia) untuk mengimbangi kuasa besar Amerika Syarikat (AS) dalam sistem antarabangsa. China yang selama ini terpaksa tunduk dan diawasi oleh AS dalam tuntutannya ke atas Taiwan kini dapat menggunakan model TRA ini bagi membolehkan China memantau dan mengawasi perluasan kuasa AS di Timur Tengah dan antarabangsa di samping memiliki peluang besar untuk muncul sebagai kuasa pengimbang dalam sistem antarabangsa. Kajian ini turut menyatakan keberkesanan cegahrintang (deterrence) TRA dan model ini dapat digunakan oleh China untuk diaplikasikan dengan Palestin melalui PRA yang dapat membawa kepada keamanan dan kemakmuran sejagat.
\end{abstract}

Kata kunci: konflik Israel-Palestin, hubungan China-Taiwan, Palestine Relations Act (PRA)

\section{China Opportunity to Apply Taiwan Relations Act (TRA) in Israeli-Palestine Conflict as Palestine Relations Act (PRA) and Extended Powers to the Islamic Conference (OIC) and The Non-Aligned Movement (NAM)}

\begin{abstract}
Resolution of the Israel-Palestinian Conflict has been a global agenda involving not only specific countries but also involving international organizations such as the United Nations (UN), the
\end{abstract}


Organisation of Islamic Cooperation (OIC) and the Non-Aligned Movement (NAM) which has failed to be resolved since 1948. Attacks on the country and the loss of lives of Palestinians have become common issue in the international security scenario. China which is one of the superpowers and a member of the UN Security Council has paid attention to the fate of Palestine has attracted attention as a country that capable of bringing about a solution to the conflict. At the same time China also has the opportunity through the concept of United States-Taiwan relations in the Taiwan Relations Act (TRA) as a solution model that will provide great benefits to Palestine and China itself in terms of political, economic and internal problem solving of China. The objective of this study is to explain the concept of TRA can be used as a basis for the formation of the Palestine Relations Act (PRA) between China and Palestine which will provide opportunity to expand influence to 57 OIC countries and 120 NAM countries that directly support China to replace Soviet Union (Russia) to create balance of power with United States (US) in the international system. China, which has been subject to the US in its claim on Taiwan, can utilize this TRA model to enable China to monitor and observe the expansion of US power in Middle East and internationally while having a great opportunity to emerge as a balancing power in the international system. This study also states the deterrence effectiveness of TRA and this model can be used by China to be applied with Palestine (PRA) which could lead to global peace and prosperity.

Keywords: Israel-Palestine conflict, China-Taiwan relations, Palestine Relations Act (PRA)

\section{Pengenalan}

Konflik Israel-Palestin wujud semenjak tertubuhnya Israel pada tahun 1948 yang mana setiap tahun Palestin menjadi mangsa kerakusan Israel yang mengorbankan nyawa manusia yang gagal diselesaikan setelah sekian lama. Kemunculan China yang mengutarakan empat cadangan penyelesaian konflik pada 16 Mei 2021 dalam Majlis Keselamatan PBB dengan menegaskan penyelesaian "dua buah negara" sebagai teras penyelesaian. Kemunculan kuasa veto dalam memperjuangkan nasib Palestin daripada penindasan Israel telah menarik perhatian dunia mengenai konflik dan pengaruh China di peringkat antarabangsa. Sekiranya dilihat dengan mendalam China memiliki kelebihan dalam menyelesaikan konflik dan dapat meningkatkan imej, pengaruh dan kuasa China di peringkat antarabangsa berdasarkan aplikasi model Taiwan Relations Act (TRA) oleh China dalam konflik Israel-Palestin. Ini kerana AS yang merupakan kuasa veto dunia telah menggunakan isu dalaman China iaitu konflik China-Taiwan yang dijadikan asas kepada AS untuk membentuk TRA yang secara langsung membolehkan AS memantau dan mengawasi China semenjak tahun $1979^{1}$. Perjanjian TRA tidak menjejaskan hubungan kedua-dua kuasa besar dan dalam masa yang sama AS berjaya melindungi Taiwan. Namun dengan termeterainya TRA ia telah menjejaskan imej China kerana ia menggambarkan China diawasi dan terpaksa akur dengan kuasa AS walaupun membabitkan isu dalaman China ${ }^{2}$. Model TRA ini dapat memberikan kelebihan kepada China untuk diaplikasikan dalam konflik Israel-Palestin. Di sini ia memberikan peluang yang sama untuk China mewujudkan Palestine Relations Act (PRA) dengan Palestin bagi memantau dan mengawasi perluasan kuasa AS di Asia Barat. Malah model PRA ini dapat membuka peluang kepada China untuk meningkatkan pengaruh, kuasa dan pasaran kepada 57 buah negara OIC dan NAM yang secara langsung dapat menyaingi dominasi AS dalam sistem antarabangsa. Melalui PRA kuasa besar China akan dapat menyelesaikan isu Palestin yang selama ini 57 buah negara OIC dan 120 buah negara NAM gagal menyelesaikan dan ia akan meningkatkan sokongan kepada China sekali gus dapat menyelesaikan isu dalaman yang berkaitan etnik Uighur di Xinjiang.

\footnotetext{
${ }^{1}$ Richard C. Bush (2017). A One-China Policy Primer. East Asia Policy Paper. 10 March. Hlm 1-30. https://www.brookings.edu/wp-content/uploads/2017/03/one-china-policy-primer-web-final.pdf 2 Chen Qimao (1987). The Taiwan Issue and Sino-U.S. Relations: A PRC View. Asian Survey.Vol. 27 (11). November.hlm 1161-1175. https://doi.org/10.2307/2644720
} 
DOI: https://doi.org/10.47405/mjssh.v6i6.840

\title{
Konflik Israel-Palestin Sebagai Mesej Israel dan AS Kepada Asia Barat dan Antarabangsa
}

Konflik Israel-Palestin sememangnya telah lali dengan isu kekejaman dan penindasan Israel ke atas Palestin dan negara Arab lain. Saban tahun semenjak penubuhan Israel pada tahun 1948, dunia dipamerkan dengan pembunuhan dan penindasan yang tidak berkesudahan sehingga ke hari ini. Ia adalah kaedah kepada Israel untuk menyampaikan mesej kepada Asia Barat dan antarabangsa mengenai status semasa Israel dan AS yang mendominasi sistem antarabangsa ${ }^{3}$. Kemelut kekejaman Israel ke atas Palestin ini telah menjadi agenda global kepada masyarakat dunia dan negara Islam lain bagi membendung kekejaman ke atas orang awam. Operasi ketenteraan Israel ke atas masyarakat yang lemah Palestin adalah diibaratkan pertembungan antara negara kuat dengan negara yang lemah yang mana Palestin menjadi mangsa. Serangan rejim Israel ke atas Palestin sekiranya dilihat dalam konteks yang lebih luas boleh dianggap sebagai "latihan ketenteraan". Mengapa? Dari perspektif Israel, Palestin dan Hamas hanyalah sebagai "bahan sasaran" dalam latihan ketenteraan. Sememangnya serangan ketenteraan yang dibuat selama ini hanyalah menjadikan wilayah dan negara Palestin sebagai "training ground" bagi memastikan mesej kekuatan ketenteraan dapat disampaikan kepada negara rantau Asia Barat dan antarabangsa mengenai status ketenteraan Israel dan dominasi kuasa AS.

\begin{abstract}
"Zaman pasca-Perang Dingin membuka ruang yang sangat luas untuk perdagangan senjata. Pembabitan ini bukan saja membantu perkembangan ekonomi, menerusi penyediaan kerja kepada ahli sains, juruteknik dan anggota tentera dan dalam bentuk pulangan tukaran asing, malah membolehkan Barat menguji-kaji senjata terbarunya dan merancakkan lagi saingan. Barat juga memastikan agar dunia luar berterusan tunduk kepadanya. Amerika dan Perancis adalah antara peniaga senjata terbesar dan negara Timur Tengah adalah antara pembeli paling aktif. Amerika mengeksport senjata bernilai AS\$25 bilion setahun, manakala Perancis pula mengeksport senjata bernilai AS\$11.4 bilion setahun akhir-akhir ini ${ }^{4, ”}$.
\end{abstract}

\section{Israel Kuasa Tentera}

Israel merupakan sebuah negara yang memiliki kekuatan ketenteraan yang kuat berbanding negaranegara Arab lain di Asia Barat. Sejarah pembangunan Weapon of Mass Destruction (WMD) Israel bukan tuduhan yang kabur, malah ia "terang lagi bersuluh". Perdana Menteri Israel, David Ben Gurion telah menjadi pemimpin yang bertanggungjawab merangka "program rahsia" pemilikan senjata nuklear Israel dan usaha ini telah membuahkan hasil apabila berjaya membina loji nuklear pertamanya di Dimona pada tahun 1956 dengan bantuan Perancis. Perancangan ini telah berjaya merintis kepada penghasilan senjata nuklear (WMD) pertama Israel menjelang tahun 1967 seiring dengan proses pembangunan program peluru berpandu sebagai pelengkap pembangunan senjata WMD Israel. Menjelang tahun 1966, Israel dengan bantuan Perancis telah berjaya memiliki 30 buah peluru berpandu dan ia telah mendorong Israel mula membangunkan senjata WMD dengan tangan sendiri peluru berpandu jarak dekat yang dikenali sebagai Jericho I pada tahun 1974. Ujian nuklear Israel yang dijalankan pada tahun 1979 di Pantai Timur Afrika Selatan telah membawa kepada kemunculan Israel sebagai sebuah kuasa nuklear baru dunia. Kejayaan pembangunan peluru berpandu Jericho I (MD-620) telah merangsang kemajuan program pembangunan senjata WMD Israel apabila berjaya membangunkan peluru berpandu jarak sederhana Jericho II yang mampu mencapai sasaran sehingga ke Soviet Union dalam lingkungan 1,500 kilometer pada tahun 1987. Pembangunan senjata WMD Israel semakin berkembang sehingga tahun 1988 apabila Israel telah memiliki peluru berpandu jarak jauh (ICBM) yang mampu membawa peledak nuklear melebihi 7,000 km. Pemilikan senjata nuklear Israel mula mendapat perhatian negara serantau dan masyarakat antarabangsa apabila Israel tidak menandatangani perjanjian Perjanjian Pengawalan Senjata Nuklear (NPT) yang ditubuhkan semenjak tahun $1968^{5}$.

\footnotetext{
${ }^{3}$ Ramli Abdul Samad (1994). Kesan perlumbaan senjata. Berita Harian. 30 Jun 1994. Hlm 10

${ }^{4}$ Kuasa Ekonomi Matlamat Barat. Berita Harian. 4 Oktober 1995. Hlm 8

5 Untuk keterangan lanjut lihat Zeev Rosenhek, Daniel Maman dan Eyal Ben-Ari (2003). The Study of War and the Military in Israel: An Empirical Investigation and a Reflective Critique. International Journal of Middle East Studies. Vol. 35 (3). August.hlm 461-484
} 
Sehingga kini, Israel dan beberapa buah negara kuasa nuklear lain masih belum dan tidak mengiktiraf perjanjian NPT kerana ia dianggap sebagai perjanjian yang gagal mengawal perebakan nuklear di dunia. Pada tahun 2003, Natural Resources Defense Council AS telah melaporkan bahawa sehingga kini, Israel telah pun memiliki sekurang-kurangnya 200 peledak nuklear dan senjata WMD lain. Pendedahan bekas juruteknik nuklear Israel iaitu Mordechai Vanunu pada 30 Mac 2003 mengenai program pembangunan nuklear Israel telah menjadi bukti kepada masyarakat dunia dengan program senjata WMD Israel yang berkembang akibat daripada kelemahan International Atomic Energy Agency (IAEA) yang gagal mengawal percambahan nuklear Israel. Sehingga kini, loji nuklear Rafael dan Yodefat dan Palmikhim, Soreq dan Dimona telah bertindak sebagai loji dan lokasi utama penghasilan senjata nuklear, peluru berpandu, penyelidikan dan sistem persenjataan nuklear Tel Aviv. Israel turut membangunkan senjata WMD lain seperti senjata kimia dan biologi di Nes Zionyaa. Bekas juruteknik nuklear Israel turut mendedahkan lokasi penyimpanan persenjataan nuklear dan konvensional di Be'er Yacov dan Eilabun, manakala The Bor telah bertindak sebagai pusat perancangan strategi dan kawalan bersama-sama dengan Tel Nof yang menjadi badan yang bertanggungjawab melaksanakan perancangan nuklear. Natural Resources Defense Council AS pernah melaporkan bahawa sehingga 2003, Israel telah pun memiliki antara 200-300 peledak nuklear dan senjata WMD lain ${ }^{6}$. Malah Israel turut memiliki pelbagai jenis peluru berpandu jarak jauh termasuk Jericho yang mampu mencecah 7,000 km. Dari sudut kekuatan konvensional, Israel turut memiliki ketenteraan yang moden dan dilengkapi dengan persenjataan moden dan canggih serta dapat digerak atur dengan cepat ${ }^{7}$. Israel hakikatnya tidak perlu menghantar bala tentera dan mengaktifkan kesemua cabang angkatan bersenjatanya semata-sama bagi menghapuskan Hamas atau rakyat Palestin. Ini kerana Israel pada ketika ini merupakan kuasa nuklear dan kuasa ketenteraan di Asia Barat. Dalam laporan bertajuk "The Third Temple's Holy of Holies: Israel's Nuclear Weapons" pegawai tentera udara AS, Kol Warner Farr pada Julai 2002 menyatakan :-

\section{"Pertahanan negara Israel itu berkembang pesat daripada 13 senjata nuklear pada 1967 kepada 400 senjata nuklear ${ }^{8 ” .}$}

\section{Mesej Kuasa AS Sebagai Kuasa Dominasi Sistem Antarabangsa}

Campur tangan kuasa besar AS dan sekutunya yang berpihak kepada Israel telah menjadi perkara yang sering mendapat perhatian dan dibincangkan oleh masyarakat dunia dan organisasi antarabangsa. Pengamalan dasar "pre-emptive" oleh Israel semenjak tahun 1967 adalah dasar yang akan mendorong kepada penafian kedaulatan negara lain, mementingkan kepentingan negara sendiri, menghalalkan serangan ke atas negara lain, tidak menghormati jiran, menafikan nilai-nilai kemanusiaan dan tidak mempertimbangkan nilai-nilai murni dalam kehidupan. Apa yang perlu kita fahami ialah dasar yang diamalkan oleh sebuah negara akan bertindak sebagai asas kepada tindakan oleh sesebuah negara tersebut. Selagi mana dasar ini menjadi intipati pegangan oleh rejim Israel, maka ia akan mengundang kepada berlakunya kekejaman seperti mana yang telah dilakukan selama ini. Pengamalan dasar "preemptive" oleh sesebuah negara akan mewujudkan satu ruang kepada negara tersebut untuk cenderung melakukan serangan yang membawa kepada berlakunya pencabulan terhadap hak masyarakat dan kedaulatan negara lain. Strategi "pre-emptive" yang diamalkan oleh Israel telah menyaksikan berlakunya peperangan besar seperti Perang Arab-Israel 1967 dan 1973, tragedi Sabra dan Shatila pada 16 September 1982, Perang Israel-Lubnan pada Julai 2006 dan serangan ke atas masyarakat Palestin sehingga ke hari ini telah mengorbankan lebih daripada ratusan ribu nyawa manusia yang tidak berdosa. Dengan menganggap semua masyarakat yang mengelilingi Israel sebagai ancaman, strategi "preemptive" tidak akan mengambil kira sasaran sama ada orang awam atau tentera. Apa yang jelas, pengamalan strategi "pre-emptive" ini akan menjadi enjin yang membawa kepada tindakan kekejaman dan penindasan oleh Israel.

\footnotetext{
${ }^{6}$ Untuk keterengan lanjut lihat Richard A. Bitzinger (2018). Military-Technological Innovation in Small States: The Cases of Israel and Singapore. Research Brief. Study Of Innovation And Technology In China. 4 May 2018.hlm 1-4 https://escholarship.org/uc/item/7vp2x155

7 Dan Peled (2001). Defense R\&D and Economic Growth in Israel:A Research Agenda. Department of Economics, University of Haifa. March https://www.cairn.info/revue-journal-of-innovation-economics2013-2-page-37.htm

${ }^{8}$ Israel Miliki 400 Bom Nuklear. Berita Harian. 6 Julai 2002. hlm 22
} 
Konflik Israel-Palestin dan negara Arab semakin rumit apabila adanya campurtangan kuasa besar seperti AS dan Britain yang menyokong pengamalan strategi "pre-emptive" Israel". Serangan "pre-emptive" rejim Israel ke atas masyarakat dan negara serantau telah mendapat restu dan sokongan kuasa dominasi dunia. Dengan sokongan dua buah negara kuasa veto, strategi "pre-emptive" Israel semakin kukuh yang akan terus membenarkan pembunuhan, kekejaman dan penindasan ke atas masyarakat Arab. Dengan kata lain, kekejaman Israel tidak dapat dihentikan selagi mana Israel masih mengamalkan dasar "preemptive". Dasar pertahanan ini akan menimbulkan satu kecenderungan berlakunya konflik, peperangan dan menimbulkan dilema keselamatan bagi negara-negara lain. Keadaan ini secara langsung akan mencetuskan ketegangan dan kebimbangan terhadap negara serantau ${ }^{10}$.

Melalui serangan ke atas Palestin, negara Asia Barat pastinya akan sedar tentang "status semasa" kemampuan, pengaruh dan hubungan rapat Israel dengan kuasa besar dunia AS. Tindakan AS yang "menutup mata" dengan kekejaman ini telah memberi isyarat atau mesej kepada masyarakat dunia dengan "status semasa" dasar dan hubungan diplomatik yang rapat yang terjalin antara kedua-dua negara ini. Kekejaman Israel ini juga berjaya memberi mesej kepada masyarakat dunia bahawa Israel masih berjaya mengekalkan status "timbalan sherrif" yang disandang semenjak 1948 sehingga kini. Malah "lesen kekejaman" telah diperluaskan oleh AS yang mana Israel boleh bertindak ke atas mana-mana negara khususnya di Asia Barat dengan menggunakan alasan memerangi keganasan. Ia juga telah memberi mesej kepada negara seteru AS seperti Iran, Syria, Lebanon dan sebagainya bahawa Israel mampu bertindak seperti mana serangan yang dilakukan ke atas Palestin pada hari ini. Serangan ke atas Palestin umumnya ketika ini juga adalah serangan psikologi Israel ke atas negara Asia Barat dan masyarakat dunia. Israel cuba memaparkan kepada masyarakat dunia bahawa Israel bukan sahaja memiliki kekuatan ketenteraan yang moden dan kuat, malah Israel turut cuba mempamerkan pengaruhnya dalam sistem antarabangsa yang "kebal" daripada hukuman masyarakat antarabangsa. Azmi Hassan (2003) menyatakan :-

\begin{abstract}
"AS sengaja tidak mahu memahami bahawa isu layanan tidak adil terhadap orang Islam amnya dan rakyat Palestin khasnya adalah punca utama mereka yang terdesak melakukan tindakan yang sukar diterima oleh sesetengah masyarakat. Rakyat Palestin sehingga hari ini yang menjadi pelarian di tanah air sendiri dikatakan menjadi symbol perjuangan yang digelar sebagai keganasan oleh sesetengah pihak ${ }^{11}$, .
\end{abstract}

\title{
Model Taiwan Relations Act (TRA) Dalam Konflik China-Taiwan
}

Persoalan yang sering ditimbulkan adalah apakah jalan penyelesaian yang terbaik dalam menyelesaikan masalah dan menyekat peperangan yang membabitkan Israel dan Palestin? Konflik yang dihadapi oleh Palestin telah cuba diperjelaskan oleh para sarjana yang mengaitkan status negara Palestin yang tidak diiktiraf oleh semua negara yang membawa kepada kelemahan kepada Palestin untuk membentuk sebuah negara yang berstruktur dan lengkap. Isu status negara dan kedaulatan Palestin menjadi faktor utama yang dikaitkan dengan malapetaka yang dihadapi oleh Palestin semenjak tertubuhnya Israel pada tahun 1948. Dalam kajian ini, model perlaksanaan Taiwan Relations Act (TRA) yang membabitkan kerjasama AS dengan Taiwan dapat digunakan untuk diaplikasikan dalam konflik Israel-Palestin sebagai kaedah penyelesaian.

Taiwan adalah wilayah sebahagian daripada China yang telah mencapai kemerdekaan pada tahun 1949. China tidak mengiktiraf kewujudan Taiwan sebagai negara dan bertegas untuk menjadikan Taiwan sebagai sebahagian daripada wilayahnya manakala bagi pihak Taiwan pula menganggap negaranya

\footnotetext{
${ }^{9}$ Sara Sudetic (2014). Pre-Emption and Israeli Decision-Making in 1967 and 1973. 16

March. https://www.e-ir.info/2014/03/16/pre-emption-and-israeli-decision-making-in-1967-and-1973/

10 Konflik Israel-Palestin ancam Asia Barat. Harian Metro. 19 Mei 2021

https://www.kosmo.com.my/2021/05/19/konflik-israel-palestin-ancam-asia-barat/

11 Azmi Hassan (2003). Singapura contohi Amerika mantap pertahanan `Homeland'. Berita Harian. 17

Mei. hlm 10
} 
DOI: https://doi.org/10.47405/mjssh.v6i6.840

adalah sah dan merdeka yang dikenali sebagai Republic of China (ROC) ${ }^{12}$. Pada tahun 2001, AS telah menjelaskan amalan demokrasi negara Taiwan telah berjaya mewujudkan masyarakat China yang demokratik yang mana melalui pertumbuhan ekonomi ia telah membawa kepada liberalisasi politik serta usaha Taiwan ini boleh menjadi contoh kepada negara China. Kuasa besar China turut menegaskan untuk menggunakan kekerasan ke atas Taiwan, yang menganggap Taiwan sebagai wilayah pembelot sekiranya Taiwan cuba menuntut kemerdekaan ${ }^{13}$.

"Bagi memastikan Taiwan sebagai sebahagian wilayahnya, China telah mengambil pendekatan membangunkan ketenteraan dan mengadakan latihan di Selat Taiwan bagi menyampaikan mesej kepada Taiwan agar tidak menuntut kemerdekaan ${ }^{14, "}$.

Walau bagaimanapun kewujudan Taiwan sebagai negara tidak diiktiraf oleh semua 193 buah negara dalam PBB. Keadaan ini menjadikan Taiwan dalam dilema dalam tuntutannya sebagai sebuah negara yang merdeka. Persoalannya mengapa sehingga ini Taiwan boleh mengekalkan kelangsungan hidup, mampu mengelakkan ancaman keselamatan dan berkembang maju dalam aspek politik, ekonomi, sosial dan pertahanan sedangkan Taiwan adalah negara yang tidak mendapat pengiktirafan oleh negara dalam sistem antarabangsa?

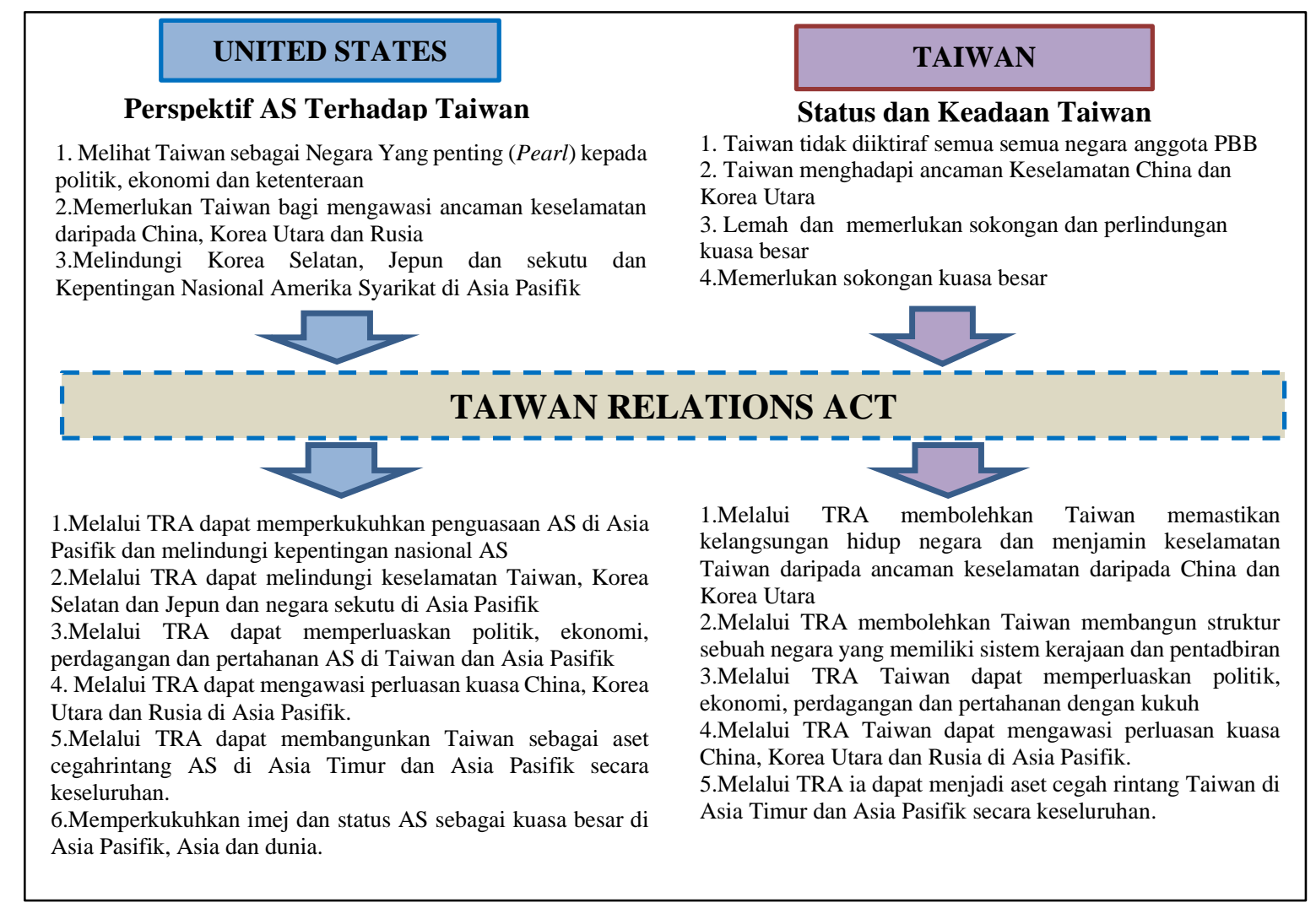

\section{Kelansungan Hidup (Survival Of The States) Taiwan}

Kunci kepada kelangsungan hidup, pengekalan keamanan dan kemajuan Taiwan adalah terletak kepada kewujudan TRA pada 10 April 1979 yang membabitkan secara perundangan dan hubungan antara negara AS dan Taiwan yang mana AS memberikan jaminan dalam aspek keselamatan, politik, ekonomi

${ }^{12}$ Douglas McCready (2003). Crisis Deterrence In The Taiwan Strait. November. http://ww2.usc.cuhk.edu.hk/PaperCollection/webmanager/wkfiles/2929_1_paper.pdf

13 Asean pasaran baru senjata dunia. Berita Harian. 17 Februari 1996. Hlm 1

${ }^{14}$ Asia Hadapi Konflik Politik. Berita Harian. 24 Februari 1996. hlm 3 
dan sosial kepada Taiwan ${ }^{15}$. Perjanjian TRA adalah membabitkan 18 Section yang mana Taiwan telah diberikan jaminan dan menjadi tanggungjawab AS dalam perundangan dari sudut keselamatan dan pertahanan sekiranya Taiwan diancam ${ }^{16}$.

\title{
“Amerika masih lagi pembekal senjata utama kepada Taiwan sekalipun mengubah pengiktirafan daripada Taipei kepada Beijing pada 1979"17,.
}

Kekuatan perjanjian ini telah dilihat oleh China, Korea Utara dan Rusia sebagai jaminan keselamatan kepada Taiwan dan menjadi deterrence (cegah rintang) kepada ancaman keselamatan. Dalam TRA juga, Taiwan memiliki kelebihan dalam mendapatkan kelengkapan dan sistem pertahanan termaju AS seperti peluru berpandu AIM 120C, kereta kebal, pesawat pejuang dan sebagainya ditempatkan di Taiwan ${ }^{18}$. Dalam perspektif AS, Taiwan adalah negara "mutiara" (Pearl) yang menjadi negara dalam usaha AS mengawasi perkembangan dan perluasan kuasa China di Asia Timur dan Asia Pasifik. Ia menunjukkan Taiwan menjadi "aset" kepada AS untuk melindungi negara sekutu lain seperti Korea Selatan, Jepun di Asia Pasifik ${ }^{19}$. Azmi Hassan (2003) menyatakan:-

\begin{abstract}
"Di rantau Asia Pasifik hanya sekutu kuat Amerika Syarikat (AS) iaitu Taiwan yang memiliki peluru berpandu jenis ini (udara ke udara AIM 120C) untuk mengekang ancaman peluru berpandu China ${ }^{20}$... Begitu juga dengan Taiwan yang perlu mempunyai sistem pertahanan peluru berpandu kerana pemimpin mereka yang gemar beretorik dengan China mengenai isu kemerdekaan. Sukar untuk dipastikan kebenaran mengenai berita China yang menghalakan beratus-ratus peluru berpandu ke Taiwan sebagai kekangan perisytiharan kemerdekaan oleh pemimpin Taipei. Bagi AS status quo konflik China dan Korea Utara adalah menguntungkan Washington kerana AS dapat mengekang kedua-dua negara ini melalui Taiwan dan Jepun yang mempunyai sistem pertahanan peluru berpandu yang canggih dan mantap $^{21, "}$.
\end{abstract}

\section{Kemajuan Ekonomi Taiwan}

Kewujudan TRA ini telah membolehkan Taiwan berdiri sebagai negara yang lengkap dan berstruktur dengan pentadbiran dan kementerian dalam memacu kemajuan negara. Dengan wujudnya TRA, walaupun Taiwan adalah sebuah negara yang tidak mendapat pengiktirafan sepenuhnya negara dalam sistem antarabangsa, namun Taiwan telah berjaya wujud sebagai negara dan menjadi antara negara mencatat kemajuan yang besar dalam pembangunan ekonomi dan dikenali sebagai Newly Industrialized Countries $^{22}$. Kewujudan TRA telah membolehkan Taiwan menjadi destinasi pembangunan industri yang pesat hasil daripada kemajuan ekonomi tanah besar China. Taiwan telah menjadi pilihan kepada para pelabur dan pengimport produk apabila mempertimbangkan aktiviti perdagangan dan pembangunan industri ${ }^{23}$. Senario ini dapat dilihat yang mana walaupun Taiwan tidak diiktiraf sebagai negara, namun Taiwan telah mencatatkan pembangunan pesat ekonomi dan perdagangan antarabangsa.

\footnotetext{
15 Glenn R. Butterton (1997). Signals, Threats, and Deterrence: Alive and Well in the Taiwan Strait.

Catholic University Law Review. Vol 47 (1).Fall .hlm 52-92

16 Charles D. Pasquale (2007). Pivotal Deterrence and United States Security Policy in the Taiwan Strait.

Dissertations. Old Dominion University. Spring.hlm 58-95

17 Pentagon mahu jual senjata: China. Berita Harian. 2 Ogos 2003.hlm 24

18 Ramli Abdul Samad (1994). Kesan perlumbaan senjata. Berita Harian. 30 Jun 1994. Hlm 10

19 Amerika Monopoli Dagangan Senjata Konvensional. Berita Harian. 15 September 1994.hlm 10

20 Azmi Hassan (2003). Hasrat Canberra gugat Asia. Berita Harian. 13 Disember.hlm12

${ }^{21}$ Azmi Hassan (2003). Singapura contohi Amerika mantap pertahanan `Homeland'. Berita Harian. 17

Mei. hlm 10

22 David Shambaugh (1966). Taiwan's Security: Maintaining Deterrence Amid Political Accountability.

The China Quarterly, Volume 148 , December 1996. pp. 1284 - 1318.

https://doi.org/10.1017/S0305741000050633

23 Christina Majaski (2020). Newly Industrialized Country - NIC. 25 December 2020

https://www.investopedia.com/terms/n/newly-industrialized-country.asp
} 
DOI: https://doi.org/10.47405/mjssh.v6i6.840

Peningkatan pesat ekonomi Taiwan adalah dipengaruhi oleh kewujudan TRA yang berjaya menyuntik keyakinan kepada pelabur asing dari seluruh dunia mengenai status keselamatan dan kemajuan Taiwan dalam menghadapi ancaman daripada China. TRA juga turut menggambarkan sebagai "bon jaminan AS kepada Taiwan" dan berjaya menyampaikan mesej jaminan keselamatan kepada negara lain dalam sistem antarabangsa bahawa "sebuah kuasa besar dunia iaitu AS mengiktiraf negara Taiwan ${ }^{24 "}$.

\title{
TRA sebagai Deterrence Kepada Taiwan
}

Apakah kesan perjanjian TRA antara Taiwan-AS kepada China yang merupakan negara kuasa veto dan sebuah kuasa besar dunia dalam Majlis Keselamatan PBB? Walaupun China menuntut Taiwan sebagai wilayah sebahagian daripada China namun dengan adanya TRA ia menjadi sebagai "US representative" di Taiwan dan bertindak sebagai deterrence kepada Taiwan ${ }^{25}$. Ketegasan tuntutan China ke atas Taiwan sering kali dapat dilihat dengan latihan ketenteraan China yang dijalankan di Selat Taiwan dan mobilisasi penempatan kelengkapan strategik China termasuk peluru berpandu yang ditempatkan berhampiran dengan wilayah Taiwan khususnya ketika pilihan raya.

"China, sebuah kuasa nuklear, menjalankan latihan tentera secara besar-besaran termasuk melancarkan peluru berpandu di selat sempit yang memisahkan pulau itu dengan Tanah Besar. Beijing menganggap Taipei sebagai wilayah pemberontak selepas puak nasionalis Taiwan lari ke pulau itu berikutan kekalahan mereka dalam perang saudara China pada 1948. Beijing sudah memberitahu bahawa ia akan melancarkan serangan terhadap Taiwan jika pentadbiran Presiden Lee Teng-hui mahupun pemimpin lain pulau itu cuba mengisytiharkan kemerdekaan ${ }^{26, "}$.

Keberkesanan TRA ini dapat dilihat dengan tindakan AS yang menghantar kapal pengangkut ke Selat Taiwan sebagai contoh pada tahun 1996 yang berjaya mengendurkan ketegangan krisis China-Taiwan dan berjaya mengelakkan peperangan antara kedua-dua negara ${ }^{27}$. Keadaan ini telah memberikan kesan negatif dari sudut imej yang dilihat terpaksa tunduk kepada kuasa besar AS walaupun China yang pada ketika ini sedang berkembang dan berpengaruh dalam sistem antarabangsa ${ }^{28}$. Kewujudan TRA juga menjadi batasan kepada China yang merupakan kuasa besar dan kuasa nuklear Asia dalam tuntutan ke atas Taiwan yang sememangnya merupakan China ${ }^{29}$.

\begin{abstract}
"Sekalipun China masih dilihat sebagai pencabar kepentingan strategi Barat, sehingga Amerika mewujudkan kerjasama dengan Jepun untuk mengawasinya dan meneruskan penjualan senjata ke Taiwan, negara itu juga semakin dipandang sebagai rakan dagangan yang berpotensi dan bakal penyumbang kepada kejayaan blok ekonomi di Asia Jauh dan Rantau Pasifik China ${ }^{30, " ~ . ~}$
\end{abstract}

\footnotetext{
${ }^{24}$ Blazevic, Jason J. (2010). The Taiwan Dilemma: China, Japan, and the Strait Dynamic. Journal of Current Chinese Affairs. Vol 39 (4). hlm 143-173

${ }^{25}$ Lihat TRA sebagai "Diplomatic Deterrence" terhadap China. Lihat Cal Clark (2010). The Taiwan Relations Act and the U.S. Balancing Role in Cross-Strait Relations. American Journal of Chinese Studies. Vol. 17 (1). April. hlm 3-18

${ }^{26}$ Kapal Perang AS Lalui Selat Melaka. Berita Harian. 21 Mac 1996. Hlm 23

${ }^{27}$ Susan V. Lawrence and Wayne M. Morrison (2017). Taiwan: Issues for Congress. CRS Report.

Congressional Research Service. 30 October. Hlm 1-83 https:/fas.org/sgp/crs/row/R44996.pdf

28 Thomas J. Christensen (1999).China, the U.S.-Japan Alliance, and the Security Dilemma in East

Asia.International Security. Vol. 23 (4). Spring. pp. 49-80w

${ }^{29}$ Lindsay Hughes (2021). To Deter China, Increase Taiwan's International Relations. Indo-Pacific Research Programme.3 March 2021

https://www.futuredirections.org.au/publication/to-deter-china-increase-taiwans-international-relations/
}

${ }^{30}$ Kuasa Ekonomi Matlamat Barat. Berita Harian. 4 Oktober 1995. Hlm 8 
DOI: https://doi.org/10.47405/mjssh.v6i6.840

\title{
Palestin Adalah Peluang Kepada China
}

Perjanjian damai dan usaha mewujudkan keamanan telah dikemukakan semenjak penubuhan Israel pada tahun 1948 lagi, namun realitinya sehingga kini ia masih kekal dengan kegagalan dalam menyelesaikan masalah yang sebenar iaitu keselamatan dan pertahanan Palestin yang sering menjadi mangsa kekejaman Israel. Perjanjian damai hanyalah bersifat berkuat kuasa di atas kertas, namun hakikatnya kekejaman dan penindasan Israel masih dilakukan secara terang-terangan. Masyarakat antarabangsa telah mengemukakan pelbagai pelan damai, menggesa campur tangan PBB, NAM, OIC dan pelbagai pendekatan unilateral untuk mencari jalan penyelesaian masih gagal dalam mewujudkan keamanan dan menghentikan kekejaman dan penindasan Israel. Berdasarkan kegagalan demi kegagalan ia telah menjadi agenda global kepada negara yang dapat membawa perubahan dan penyelesaian dalam konflik Israel-Palestin. Apakah strategi dan kaedah yang dapat digunakan dalam menyelesaikan permasalahan ini?

Palestin merupakan wilayah yang telah wujud sebelum 1945 lagi manakala kewujudan Israel adalah pada tahun 1948 hasil daripada sokongan Britain yang membolehkan berdirinya Israel sebagai sebuah negara walaupun pendudukan ini merupakan jajahan haram ke atas tanah rakyat Palestine. China telah memiliki hubungan awal dengan Palestin semenjak era 1970-an lagi ${ }^{31}$.

\begin{abstract}
"For the conflict between Palestinian Arabs and Jews, China has not always maintained the same views and will change according to the changing situation, be it ideological reason or self-interest considerations. In general, China's positions on the Palestine and Israel issue can be roughly divided into the following stages: before the founding of the People's Republic, China show sympathy towards the Arabs and the Jews equally; in 1949-1959, China-Israel relation changed from intimate contact to alienation; in 1959-1969, China's policy was pro-Arabs and antiIsrael, and give full support to the Palestine Liberation Organization; in 1969-1979, China reduced its support for the Palestine Liberation Organization and also its criticism towards Israel; in 1979-1989, China recognized Israel's "right of independence and survival" and persuade the two parties to negotiate and make peace; in 1989-1999, China actively promoted the Middle East peace process; in 1999-2013, China actively participated in the Middle East peace process; since 2013, China began to actively participate in the Middle East hot issues ${ }^{32}$ ".
\end{abstract}

Seperti Taiwan, Palestin merupakan negara yang tidak mendapat pengiktirafan sepenuhnya negara dalam sistem antarabangsa. Sehingga Ogos 2018 Palestin hanya mendapat pengiktirafan sebanyak 137 buah negara daripada 193 negara dalam PBB. Keadaan ini mempengaruhi Palestin untuk mewujudkan sistem sebuah negara yang berstruktur dan tersusun. Ia juga menyebabkan Palestin sering kali menjadi sasaran kepada serangan Israel. Di sini menunjukkan situasi Palestin adalah seperti Taiwan yang memerlukan sokongan mana-mana kuasa besar khususnya kuasa veto PBB. Mengapa Israel yang kecil dan wujud semenjak tahun 1948 mampu berdiri dan membangunkan negara malah mampu menyerang negara-negara yang lain? Mengapa Iran dan Korea Utara yang dipromosikan oleh AS sebagai negara yang mengancam keselamatan global mampu berjaya dan membangunkan negara dan pertahanan dengan berjaya dan tidak diancam oleh negara lain? Ini kerana adanya kuasa besar veto yang memberikan perlindungan dan menyokong negara berkenaan.

AS melihat Taiwan sebagai negara mutiara (Pearl) manakala 56 daripada 57 buah negara Islam OIC pula melihat Palestin juga sebagai negara mutiara (Pearl) dan merupakan negara yang memiliki salah sebuah kota suci umat Islam iaitu Baitulmuqaddis. OIC semenjak 1960-an telah berusaha membantu Palestin namun gagal memberikan perlindungan sepenuhnya kepada Palestin dengan berkesan. Walaupun 56 buah negara OIC memiliki pertubuhan yang besar, namun ia masih belum cukup

\footnotetext{
${ }^{31}$ Delegation of Palestine Liberation Movement (Fateh) Arrives in Peking. Peking Review. Vol 13 (13). 27 Mac 1970. Hlm 4-5. Hari ini dikenali sebagai PLO (Palestine Liberation Organization) Lihat juga Chairman Arafat Greets National Day. Peking Review. Vol13 (42). 16 October 1970. Hlm 2

32 Yang Chen (2017). China's Position on the Palestine-Israel Issue: A Historical Perspective. Middle

Eastern Studies. hlm 1-21. https://dergipark.org.tr/tr/download/article-file/887461
} 
memastikan keselamatan dan pertahanan Israel dilindungi. Kejayaan mana-mana kuasa veto yang berjaya melindungi dan memberi jaminan keselamatan kepada Palestin akan dilihat sebagai pembela dan merintis kerjasama erat dengan negara Islam OIC yang lain. Malah dari sudut pasaran ekonomi ia memberikan peluang kepada pasaran yang luas di samping memperkukuhkan pengaruh dan kuasa negara berkenaan dalam sistem antarabangsa.

\title{
Bagaimanakah China dapat Memanfaatkan Model TRA ini dalam Konflik Israel- Palestin?
}

Mengapakah China dilihat memiliki peluang dalam mewujudkan PRA dengan Palestin? Model TRA adalah membabitkan kesan kepada China yang mana China sendiri dapat melihat keberkesanan kewujudan perjanjian keselamatan dan perlindungan TRA antara Taiwan dengan AS. China juga dapat melihat bagaimana AS memantau dan mengawasi kuasa China di Asia Pasifik melalui Perjanjian TRA yang dapat memberikan idea dan model kepada China untuk mengadakan PRA dengan Palestin ${ }^{33}$ yang dapat memberikan peluang kepada China untuk memantau dan mengawasi perluasan kuasa AS di Asia Barat. Pada Disember 2020, Presiden China, Xi Jinping pernah menyatakan penyelesaian dua negara sebagai asas politik dalam mengakhiri krisis Palestin-Israel dan mencadangkan empat cadangan akan dilaksanakan China membabitkan isu pertikaian sedia ada. Presiden Xi Jinping mencadangkan peranan dalam membina negara Palestin dengan memegang konsep keselamatan secara umum, komprehensif dan kerjasama, terus menyelaras usaha masyarakat antarabangsa dan melaksanakan dasar perkembangan secara keseluruhan dalam mengekalkan keamanan ${ }^{34}$. Menteri Luar China, Wang Yi pada Disember 2017 menegaskan China sentiasa menyokong rakyat Palestin untuk memulihkan hak perundangannya, menyokong penubuhan Palestin yang berdaulat dan merdeka melalui sempadan 1967 berasaskan Baitulmuqaddis Timur sebagai ibu kota. Pada 14 Disember 2017 jurucakap Kedutaan China di Malaysia menyatakan :-

\begin{abstract}
"China menyokong proses keamanan Asia Barat secara teguh, menyokong penyelesaian isu Asia Barat termasuk kedudukan Baitulmaqdis menurut resolusi $P B B$, menyokong penubuhan Palestin yang berdaulat dan merdeka melalui sempadan 1967 berasaskan Baitulmaqdis Timur sebagai ibu kota. Pendirian China tidak akan berubah. China akan memainkan peranan secara bertanggungjawab dan membina dalam proses penyelesaian isu Palestin sebagai Anggota Tetap Jawatankuasa Keselamatan PBB. Kuasa Usaha Misi Tetap Republik Rakyat China ke PBB, Duta Besar Wu Haitao, pada 8 Disember lalu (2017) menegaskan pendirian China bahawa perubahan unilateral sebarang pihak akan merosakkan asas menyelesaikan isu Palestin ${ }^{35}$ ", .
\end{abstract}

Cadangan penubuhan PRA antara kuasa besar China dengan Palestin juga adalah bertepatan apabila China dilihat memperjuangkan nasib Palestin seperti cadangan Menteri Luar China, Wang Yi pada 16 Mei 2021 dalam Majlis Keselamatan Pertubuhan Bangsa-bangsa Bersatu yang mengemukakan empat cadangan dalam penyelesaian konflik Palestin-Israel secara menyeluruh yang bukan hanya dalam konflik Israel-Palestin tetapi juga konflik di Asia Barat. Antara cadangan yang diutarakan adalah :-

1. Palestin dan Israel perlu segera mengadakan gencatan senjata.

2. Bantuan kemanusiaan amat diperlukan penduduk di kawasan yang terlibat dalam peperangan. Justeru, China telah mendesak Israel untuk menunaikan kewajipan di bawah perjanjian antarabangsa, membatalkan sekatan terhadap Gaza secepat mungkin, menjamin

\footnotetext{
${ }^{33}$ Hubungan China dengan PLO dapat dilihat dalam Lillian Craig Harris (2021). China's Relations with the PLO. 4 Feb 2021.hlm 123-154.

https://www.tandfonline.com/doi/abs/10.2307/2536531? journalCode=rpal20

34 Nazura Ngah (2017). China Sokong Palestin Yang Berdaulat, Merdeka. Berita Harian. 14 Disember. https://www.bharian.com.my/berita/nasional/2017/12/363377/china-sokong-palestin-yang-berdaulat$\underline{\text { merdeka }}$

35 Ibid
} 
keselamatan dan hak penduduk awam, serta menyediakan akses kepada bantuan kemanusiaan $^{36}$.

3. Menyeru sokongan padu masyarakat antarabangsa dan UNSC untuk bertindak bagi merungkai konflik Palestin-Israel dengan memberikan sokongan teguh terhadap kaedah "penyelesaian dua negara".

4. 'Penyelesaian dua negara' adalah jalan keluar bagi menyelesaikan konflik Israel-Palestin. China turut menyokong Israel dan Palestin untuk kembali ke meja rundingan mengikut formula 'penyelesaian dua negara' secepat mungkin ke arah mewujudkan negara Palestin yang berdaulat dengan Baitulmuqaddis Timur sebagai ibu negara ${ }^{37}$.

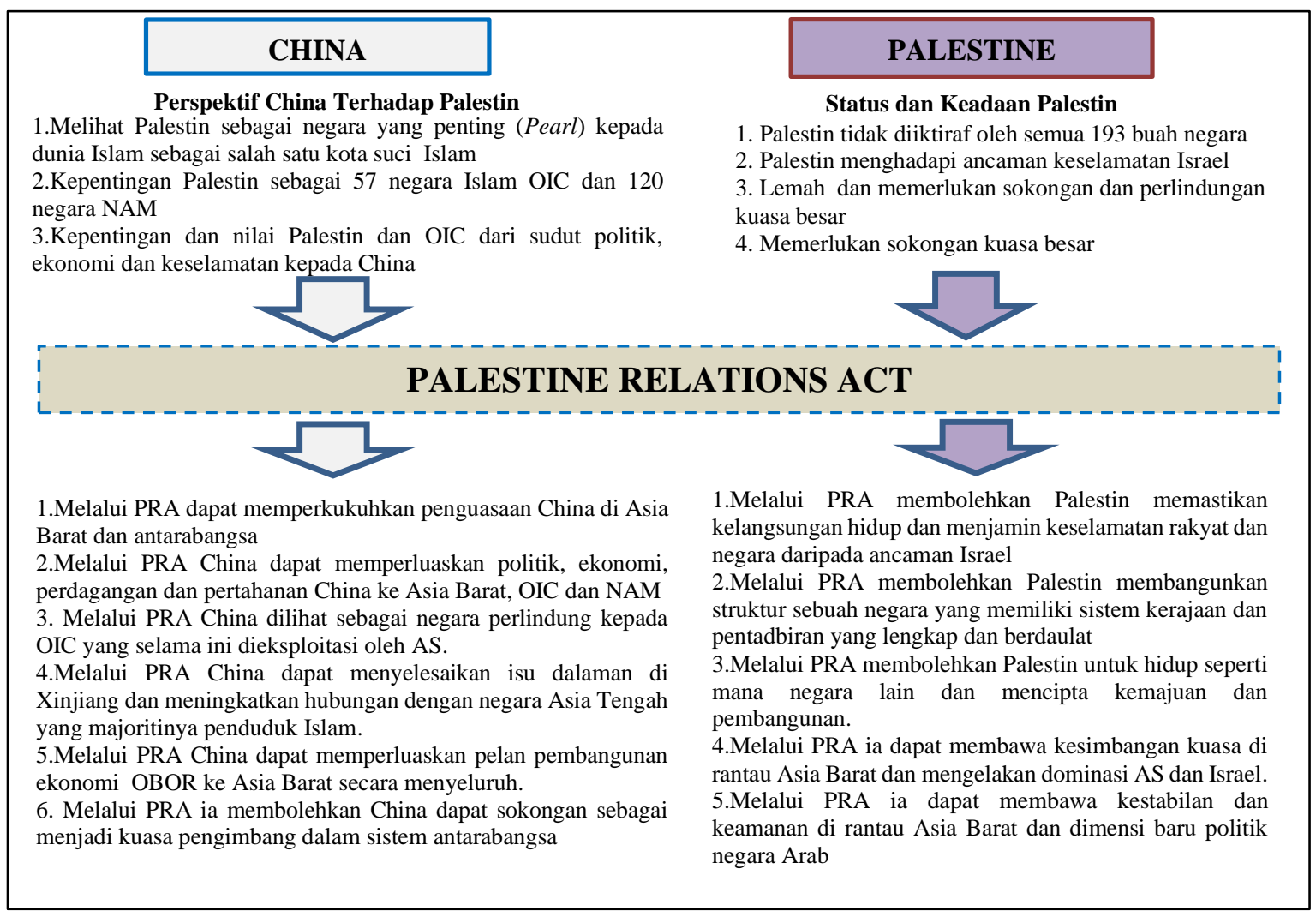

Kerjasama AS dan Taiwan dalam TRA telah menunjukkan keberkesanan dan kejayaan yang membawa kepada kewujudan Taiwan sebagai sebuah negara dan kemajuan Taiwan walaupun tidak diiktiraf oleh ke semua negara dalam sistem antarabangsa. Keberkesanan TRA ini dapat dilihat yang mana walaupun China yang merupakan kuasa veto namun terpaksa mempertimbangkan tindakan kekerasan terhadap Taiwan dalam memastikan Taiwan berada di bawah China. Malah di sini, AS dilihat berjaya menggunakan kesempatan dalam masalah dalaman China dengan menggunakan TRA yang dapat mengawasi China.

\section{China dapat Memperluaskan Pengaruh dan Pasaran Ke Negara OIC dan NAM}

Dalam konflik Israel-Palestin, China dapat menggunakan konflik ini bagi memastikan keamanan ditegakkan dan memberikan kesan yang besar kepada pengaruh China dengan mewujudkan Palestine Relations Act (PRA). Malah dengan mewujudkan PRA ia akan memberikan manfaat yang besar kepada China yang merupakan kuasa veto dunia serta dapat memperluaskan pengaruh dan meluaskan pasaran

\footnotetext{
${ }^{36}$ Shi Jiangtao (2021). China pledges US\$1 million in aid, Covid-19 vaccines to Palestinians. 21 May. https://www.scmp.com/news/china/diplomacy/article/3134375/china-pledges-us1-million-aid-covid-19vaccines-palestinians

${ }^{37}$ Konflik Palestin-Israel: China kemuka empat cadangan. Sinar Harian. 17 Mei 2021. https://www.sinarharian.com.my/article/138938/GLOBAL/Konflik-Palestin-Israel-China-kemuka-empatcadangan
} 
kepada 56 buah negara OIC dan 120 buah negara NAM. Seperti Taiwan, Palestin memerlukan sokongan dan perlindungan daripada kuasa veto seperti China bagi memastikan keselamatan dan kelangsungan hidup Palestin. Ia adalah kaedah yang sama iaitu mewujudkan TRA yang diguna pakai oleh AS dalam konflik China-Taiwan. China boleh mewujudkan PRA kaedah yang sama dalam konflik Israel-Palestin. Sokongan China kepada Palestin melalui PRA tidak menjejaskan hubungan dengan Israel dan AS seperti mana AS memberikan sokongan kepada Taiwan melalui TRA. Malah ia adalah timbal balik seperti mana sokongan yang diberikan AS kepada Taiwan dan China memberikan sokongan kepada Palestin.

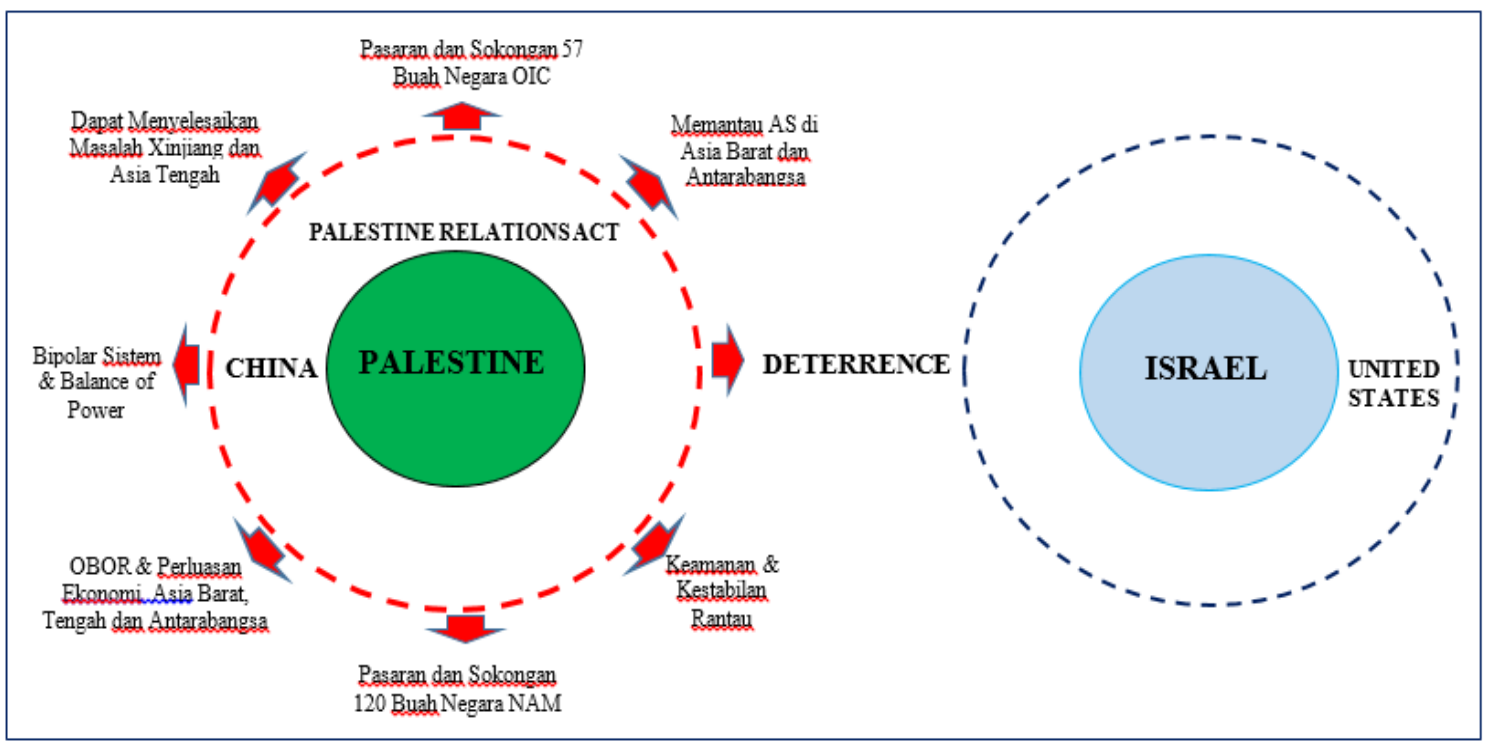

Sokongan China kepada Palestin melalui PRA akan membolehkan berdirinya Palestin sebagai negara dalam erti kata yang sebenar yang mana melalui PRA ia akan menjadi tunjang kepada pembentukan sebuah negara yang berstruktur dan lengkap. Malah melalui PRA China dapat memberikan jaminan keselamatan yang dapat memastikan nyawa rakyat dan keamanan rantau dapat ditegakkan. Malah melalui PRA juga China juga dapat menyediakan sistem keselamatan dan kelengkapan pertahanan kepada Palestin. Malah industri pertahanan China juga turut dapat diperluaskan kepada negara OIC memandangkan terdapat 57 buah negara OIC dan 120 buah negara NAM sebagai pasaran baru produk pertahanan China. Ia juga sejajar dengan dasar ekonomi China pada ketika ini yang semakin berkembang ke seluruh dunia ${ }^{38}$. Pasaran produk pertahanan dan produk-produk industri China kepada negara OIC dan NAM bukanlah perkara baru sebaliknya ia telah lama wujud ${ }^{39}$. China adalah negara yang membantu Iran membangunkan sistem pertahanan, malah Indonesia yang merupakan negara terbesar penduduk Islam juga merupakan destinasi produk pertahanan China. Begitu juga dengan Malaysia yang merupakan bekas negara pengerusi kepada OIC dan NAM turut menjadi negara yang mengimport barangan dan kelengkapan pertahanan dari China. Melalui perlaksanaan PRA, China dapat memperkembangkan konsep "One Belt, One Road"40 (OBOR) ke Timur Tengah dan memperluaskan ke seluruh dunia berikutan negara anggota OIC dan NAM wujud di seluruh dunia.

\footnotetext{
${ }^{38}$ Niv Horesh (2019). Introduction: Cina's One Belt, One Road Vision-Implications for the Middle East. Dalam Anoushiravan Ehteshami dan Niv Horesh (Edt) China's Presence in the Middle East The Implications of the One Belt, One Road Initiative. New York: Routledge. Hlm 1-7

${ }^{39}$ Hubungan China dengan PLO dapat dilihat dalam Lillian Craig Harris (2021). China's Relations with the PLO. 4 Feb 2021.hlm 123-154.

https://www.tandfonline.com/doi/abs/10.2307/2536531?journalCode=rpal20

40 Rebecca Harding (2019). China's Belt And Road Initiative And Its Impact On The Middle East And North Africa. 20 September 2019. https://internationalbanker.com/finance/chinas-belt-androad-initiative-and-its-impact-on-the-middle-east-and-north-africa/
} 


\section{China dapat Membantu Menyelesaikan Masalah Dalaman China}

Melalui penubuhan PRA, China turut memiliki peluang dalam menyelesaikan masalah dalaman yang dihadapi dengan masalah etnik Uighur di wilayah Xinjiang dan etnik minoriti lain. Melalui sokongan dan kerjasama China-Palestin, ia akan memberikan kesan kepada negara Islam OIC apabila dilihat memberikan sokongan dan perlindungan kepada Palestin yang secara langsung akan mengendurkan masalah etnik Uighur di Xinjiang untuk bekerjasama dengan kerajaan China. Malah ia akan memberikan kesan yang besar kepada kejayaan ekonomi China kerana wilayah Xinjiang dan Asia Tengah yang berada di Laluan Sutera (Silk Road) yang memiliki penduduk Islam yang besar ${ }^{41}$. Ia adalah satu pendekatan yang membolehkan China membina landasan kepada perluasan kuasa ekonomi, politik dan ketenteraan di Laluan Sutera apabila negara-negara OIC melihat China yang berjaya memecah kebuntuan dan kegagalan OIC selama ini dalam memberikan perlindungan kepada Palestin. Dalam masa yang sama China dapat menyelesaikan masalah Uighur yang menjadi isu antarabangsa. China sepatutnya menjadikan TRA sebagai model yang pernah mencalarkan imej China sebagai kaedah dalam meningkatkan imej China sebagai timbal balas terhadap AS. Kemunculan isu di Xinjiang, Tibet dan Hong Kong yang berkaitan dengan hak asasi minoriti etnik Uighur ${ }^{42}$ dan situasi rakyat Hong Kong mampu membawa kepada campur tangan kuasa AS dan sekutu dalam hal ehwal dalaman China. Kegagalan China menyelesaikan isu di Xinjiang, Tibet dan Hong Kong akan mampu membawa wujudnya "model TRA" dengan kawasan-kawasan ini dengan kuasa asing. Justeru, China perlu menjadikan model TRA untuk mewujudkan PRA dengan Palestin yang sekurang-kurang dapat mengendurkan isu yang dikaitkan dengan etnik Uighur ${ }^{43}$.

\section{China Bakal Menggantikan Kuasa Soviet Union dalam Sistem Bipolar}

Keruntuhan Soviet Union pada tahun 1991 telah membawa kepada perpecahan Kesatuan Soviet dan penurunan pengaruh Rusia dalam sistem antarabangsa daripada Bipolar sistem kepada unipolar yang didominasi oleh AS. Keruntuhan kuasa Soviet Union ini telah membuka ruang kepada "vacuum power" kepada mana-mana kuasa veto dan kuasa besar lain untuk mengambil tempat Soviet Union ${ }^{44}$. Walaupun Vladimir Putin menjadi Presiden Rusia telah menampakkan peningkatan pengaruh dan imej Rusia pasca 1991, namun ia masih gagal mendominasi sistem antarabangsa atau menyaingi kuasa besar AS. Berbeza dengan China yang mula mencatatkan pertumbuhan ekonomi yang pesat semenjak tahun 1990 sehingga kini telah membawa kemunculan China sebagai kuasa ekonomi dunia yang mampu menyaingi dominasi AS dan Jepun ${ }^{45}$. Malah kemunculan China sebagai kuasa besar turut dapat dilihat apabila AS turut bergantung pedagangan dengan China. Pada hari ini, sebarang konflik dalam perdagangan antara AS dan China akan memberikan kesan besar kepada ekonomi antarabangsa. Sebagai contoh senario ini dapat dilihat dalam krisis perdagangan dan produk syarikat Huawei Technologies yang membabitkan ketegangan antara AS dan China pada Mei 2019 telah memberikan kesan kepada ekonomi dunia. Selain itu, melalui PRA China-Palestin ia dapat menjadikan China menyerlahkan kemunculannya dalam senario antarabangsa yang menjadi kuasa yang dapat menyaingi kuasa AS selama ini yang mendominasi sistem antarabangsa. Malah ia akan memberikan peluang kepada China untuk mengisi kekosongan kuasa Soviet Union dalam sistem bipolar yang akan mengimbangi kuasa AS. Melalui penubuhan PRA

\footnotetext{
41 Asiri Mohammed Abdulrahman, Liu Cheng and Liu Xiangdong (2019). Middle-East and OBOR Trade Integration: Perspectives Analysis from Transportation Cost. Proceedings of the 2019 International Conference on E-Business and E-commerce Engineering. December 2019. Hlm 47-51. https://doi.org/10.1145/3385061.3385066

42 China didakwa memandulkan etnik Uighur secara paksa. Berita Harian. 30 Jun 2020. https://www.bharian.com.my/dunia/asia/2020/06/705542/china-didakwa-memandulkan-etnik-uighursecara-paksa

43 Isu Uighur: Hampir 40 negara desak China. Harian Metro. 7 Oktober 2020 https://www.hmetro.com.my/global/2020/10/628193/isu-uighur-hampir-40-negara-desak-china 44 Donald S. Zagoria (1991). The End of the Cold War in Asia: Its Impact on China. The China Challenge: American Policies in East Asia. Proceedings of the Academy of Political Science. Vol. 38 (2). Hlm 1-11 45 Barbara Lippert dan Volker Perthes (2020) Strategic Rivalry Between United States And China Causes, Trajectories, And Implications For Europe. SWP Research Paper 2020/RP. 4 April 2020.hlm 1-53: 10.18449/2020RP04
} 
juga China akan turut dapat memperkukuhkan pengaruh dan kuasa sebagai kuasa ekonomi dan politik antarabangsa. Selama ini penubuhan TRA telah mencalarkan imej China sebagai kuasa besar dan kuasa ekonomi dengan "bayangan dominasi AS", namun melalui PRA China akan membolehkan imej dan status China meningkat melalui PRA yang membolehkan penyampaian mesej kepada AS dengan kemampuan China untuk membayangi pergerakan AS di Asia Barat dan antarabangsa.

\section{Kesimpulan}

Konflik Israel-Palestin merupakan konflik yang tercetus semenjak tertubuhnya negara Israel semenjak tahun 1948. Konflik kedua-dua negara telah menjadi salah satu kegagalan PBB dalam mencari penyelesaian sehingga kini. Pertubuhan OIC dan NAM turut berusaha mencari jalan penyelesaian dalam memastikan keselamatan nyawa orang awam dan negara Palestin tidak menjadi sasaran oleh Israel dan AS dalam percaturan kuasa di Asia Barat dan antarabangsa. China yang merupakan salah sebuah negara kuasa veto PBB adalah memiliki model dan idea yang dapat diguna pakai dalam penyelesaian dalam konflik Israel-Palestin yang dapat memberikan manfaat yang besar kepada China. Kerjasama ASTaiwan dalam TRA telah menyebabkan imej China tercalar dan diawasi oleh AS melalui Taiwan. Model TRA ini berjaya bertindak jaminan keselamatan yang memastikan kelangsungan hidup Taiwan walaupun China menuntut Taiwan sebagai sebahagian dari wilayahnya. Model TRA ini turut boleh dijadikan oleh China bagi diaplikasikan dalam konflik Israel-Palestin dengan memberikan sokongan dan kerjasama dengan Palestin sebagai PRA. Pembentukan PRA ini akan membolehkan China membawa keamanan di Asia Barat dan memberikan faedah yang besar iaitu 57 buah negara OIC dan 120 NAM yang dapat memberikan sokongan dan peluang pasaran yang besar sejajar dengan proses perluasan kuasa ekonomi China. Malah China selama ini telah pun berusaha menegaskan keperluan membentuk Palestin sebagai negara berdaulat walau bagaimanapun China memerlukan model kerjasama yang lebih konkrit. Justeru, model TRA ini dapat diguna pakai oleh China dalam menyelesaikan konflik Israel-Palestin di samping imej China meningkat yang dapat menyaingi kuasa dominasi AS di Asia Barat. Melalui PRA juga China dapat mengendurkan dan menyelesaikan masalah dalam China yang berkaitan dengan etnik Uighur dan membuka jalan hubungan baik dengan negara di Laluan Sutera memandangkan penduduk Islam di Laluan Sutera adalah besar.

\section{Rujukan}

Asiri Mohammed Abdulrahman, Liu Cheng \& Liu Xiangdong (2019). Middle-East and OBOR Trade Integration: Perspectives Analysis from Transportation Cost. Proceedings of the 2019 International Conference on E-Business and E-commerce Engineering. December 2019. Hlm 47-51. https://doi.org/10.1145/3385061.3385066

Azmi Hassan (2003). Hasrat Canberra gugat Asia. Berita Harian. 13 Disember.

Azmi Hassan (2003). Singapura contohi Amerika mantap pertahanan `Homeland'. Berita Harian. 17 Mei.

Barbara Lippert dan Volker Perthes (2020) Strategic Rivalry Between United States And China Causes, Trajectories, And Implications For Europe. SWP Research Paper, 1-53. Doi: 10.18449/2020RP04

Berita Harian (1994)Amerika Monopoli Dagangan Senjata Konvensional. Berita Harian. 15 September 1994.

Berita Harian (1996). Asean pasaran baru senjata dunia. Berita Harian. 17 Februari 1996.

Berita Harian . (1996). Asia Hadapi Konflik Politik. Berita Harian. 24 Februari 1996.

Blazevic, J. J. (2010). The Taiwan Dilemma: China, Japan, and the Strait Dynamic. Journal of Current Chinese Affairs, 39(4),143-173

Cal Clark (2010). The Taiwan Relations Act and the U.S. Balancing Role in Cross-Strait Relations. American Journal of Chinese Studies, 17(1), 3-18

Chairman Arafat Greets National Day (1970). Peking Review, 13(42). 16 October 1970.

Charles D. Pasquale (2007). Pivotal Deterrence and United States Security Policy in the Taiwan Strait. Dissertations. Old Dominion University. Spring.

Chen Qimao (1987). The Taiwan Issue and Sino-U.S. Relations: A PRC View. Asian Survey, 27(11), 1161-1175. https://doi.org/10.2307/2644720 
China didakwa memandulkan etnik Uighur secara paksa. Berita Harian. 30 Jun 2020. https://www.bharian.com.my/dunia/asia/2020/06/705542/china-didakwa-memandulkan-etnikuighur-secara-paksa

Christina Majaski (2020). Newly Industrialized Country - NIC. 25 December 2020

Dan Peled (2001). Defense R\&D and Economic Growth in Israel:A Research Agenda. Department of Economics, University of Haifa. March https://www.cairn.info/revue-journal-of-innovationeconomics-2013-2-page-37.htm

David Shambaugh (1966). Taiwan's Security: Maintaining Deterrence Amid Political Accountability. The China Quarterly, 148, 1284 - 1318. https://doi.org/10.1017/S0305741000050633

Delegation of Palestine Liberation Movement (Fateh) Arrives in Peking. Peking Review, 13(13), 27, 45.

Donald S. Zagoria (1991). The End of the Cold War in Asia: Its Impact on China.The China Challenge: American Policies in East Asia. Proceedings of the Academy of Political Science, 38(2), 1-11

Douglas McCready (2003). Crisis Deterrence In The Taiwan Strait. November. http://ww2.usc.cuhk.edu.hk/PaperCollection/webmanager/wkfiles/2929_1_paper.pdf

Glenn R. Butterton (1997). Signals, Threats, and Deterrence: Alive and Well in the Taiwan Strait. $\begin{array}{llllll}\text { Catholic University } & \text { Law } & \text { Review. } & \text { Vol } & 47 & \text { (1).Fall }\end{array}$ .https://www.futuredirections.org.au/publication/to-deter-china-increase-taiwans-internationalrelations/https://www.investopedia.com/terms/n/newly-industrialized-country.asp

Israel Miliki 400 Bom Nuklear. Berita Harian. 6 Julai 2002.

Isu Uighur: Hampir 40 negara desak China. Harian Metro. 7 Oktober 2020 https://www.hmetro.com.my/global/2020/10/628193/isu-uighur-hampir-40-negara-desak-china

Kapal Perang AS Lalui Selat Melaka. Berita Harian. 21 Mac 1996.

Konflik Israel-Palestin ancam Asia Barat. Harian Metro. 19 Mei 2021 https://www.kosmo.com.my/2021/05/19/konflik-israel-palestin-ancam-asia-barat/

Konflik Palestin-Israel: China kemuka empat cadangan. Sinar Harian. 17 Mei 2021. https://www.sinarharian.com.my/article/138938/GLOBAL/Konflik-Palestin-Israel-Chinakemuka-empat-cadangan

Kuasa Ekonomi Matlamat Barat. Berita Harian. 4 Oktober 1995.

Lillian Craig Harris (2021). China's Relations with the PLO. 4 Feb 2021.hlm 123-154. https://www.tandfonline.com/doi/abs/10.2307/2536531 ?journalCode=rpal20

Lindsay Hughes (2021). To Deter China, Increase Taiwan's International Relations. Indo-Pacific Research Programme.3 March 2021

Nazura Ngah (2017). China Sokong Palestin Yang Berdaulat, Merdeka. Berita Harian. 14 Disember. https://www.bharian.com.my/berita/nasional/2017/12/363377/china-sokong-palestin-yangberdaulat-merdeka

Niv Horesh (2019). Introduction: Cina's One Belt, One Road Vision-Implications for the Middle East. Dalam Anoushiravan Ehteshami dan Niv Horesh (Edt) China's Presence in the Middle East The Implications of the One Belt, One Road Initiative. New York: Routledge. Hlm 1-7

Pentagon mahu jual senjata: China. Berita Harian. 2 Ogos 2003.

Ramli Abdul Samad (1994). Kesan perlumbaan senjata. Berita Harian. 30 Jun 1994.

Rebecca Harding (2019). China's Belt And Road Initiative And Its Impact On The Middle East And North Africa. 20 September 2019. https://internationalbanker.com/finance/chinas-belt-and-roadinitiative-and-its-impact-on-the-middle-east-and-north-africa/

Richard A. Bitzinger (2018). Military-Technological Innovation in Small States: The Cases of Israel and Singapore. Research Brief. Study Of Innovation And Technology In China. 4 May 2018.hlm 1-4 https://escholarship.org/uc/item/7vp2x155

Richard C. Bush (2017). A One-China Policy Primer. East Asia Policy Paper. 10 March. Hlm 1-30. https://www.brookings.edu/wp-content/uploads/2017/03/one-china-policy-primer-web-final.pdf

Sara Sudetic (2014). Pre-Emption and Israeli Decision-Making in 1967 and 1973. 16 March. https://www.e-ir.info/2014/03/16/pre-emption-and-israeli-decision-making-in-1967-and-1973/

Shi Jiangtao (2021). China pledges US\$1 million in aid, Covid-19 vaccines to Palestinians. 21 May. https://www.scmp.com/news/china/diplomacy/article/3134375/china-pledges-us1-million-aidcovid-19-vaccines-palestinians

Susan V. Lawrence and Wayne M. Morrison (2017). Taiwan: Issues for Congress. CRS Report. Congressional Research Service. 30 October. Hlm 1-83 https://fas.org/sgp/crs/row/R44996.pdf 
Malaysian Journal of Social Sciences and Humanities (MJSSH), Volume 6, Issue 6, (page 37 - 52), 2021

DOI: https://doi.org/10.47405/mjssh.v6i6.840

Thomas J. Christensen (1999).China, the U.S.-Japan Alliance, and the Security Dilemma in East Asia. International Security, 23(4), 49-80

Yang Chen (2017). China's Position on the Palestine-Israel Issue: A Historical Perspective. Middle Eastern Studies. https://dergipark.org.tr/tr/download/article-file/887461

Zeev Rosenhek, Daniel Maman dan Eyal Ben-Ari (2003). The Study of War and the Military in Israel: An Empirical Investigation and a Reflective Critique. International Journal of Middle East Studies, 35 (3), 461-484 